\title{
ELECTRICAL AND OPTICAL CHARACTERIZATION OF DIELECTRIC BARRIER DISCHARGE PRODUCED IN ATMOSPHERIC AIR
}

\author{
${ }^{2}$ R. B. Tyata, ${ }^{1}$ D. P. Subedi*, ${ }^{1}$ U. M. Joshi, ${ }^{1}$ D. K. Madhup \\ ${ }^{1}$ Department of Natural Science (Physics), Kathmandu University, Dhudikhel, NEPAL \\ ${ }^{2}$ Department of Physics, Khwopa College, Dekocha, Bhaktapur, NEPAL \\ *Corresponding author: deepaksubedi2001@yahoo.com
}

Received 15 December, 2008; Revised 11 January, 2009

\begin{abstract}
This paper reports the results concerning the production of Dielectric Barrier Discharge (DBD) at atmospheric pressure air and its electrical and optical characterization. The discharge was produced by applying high voltage AC source of frequency $(10-30) \mathrm{kHz}$ and potential difference of (0-20) $\mathrm{kV}$ across the electrodes. The discharge was characterized by measuring current and voltage with a high frequency digital oscilloscope. The optical characterization was made by taking the spectrums of discharge by optical emission spectrometer. The optical spectra in the range of $200 \mathrm{~nm}$ to $450 \mathrm{~nm}$ have been analyzed in order to estimate the electron temperature by intensity ratio method. Results showed that the electron temperature is about $1.9 \mathrm{eV}$.
\end{abstract}

Key words: DBD, emission spectra, electron temperature, non-equilibrium plasma

\section{INTRODUCTION}

In recent years, non-equilibrium plasmas under atmospheric pressure have been developed as an effective means for surface modification of polymers (Shenton and Steven, 2001; Fang Qiu and Y Luo, 2003).These plasmas possesses unique features that have led to a number of important applications such as ozone production, pollution control by oxidation of volatile organic compound or nitrogen monoxide, bio-treatment of micro-organisms by oxidation, surface treatment (thin film deposition, surface modification), UV or VUV generation, aerosol charging and electro-filtration (Hammer, 1999; Kogelschatz et al., 1999; Tepper et al. 2000; McAdams, 2001; Fridman et al., 2005). They are rapidly being popular due to their many advantages, such as having no need for expensive vacuum equipment, being low cost and simple systems, and easy to operate (Bogaerts, 2002). The existence of the thermal non-equilibrium between the electron, the ions and the neutrals is the realm of non-thermal plasmas in which the electron temperature can exceed the temperature of the heavy particles (atom, molecules, ions) by orders of magnitude. Since the ions and the neutrals remain relatively cold, these plasmas do not cause thermal damage to surfaces they may come in contact with (Borcia, 2006). This characteristics provides the possibility of using these plasmas for low temperature plasma chemistry and for treatment of heat sensitive materials including polymers and biological tissues. Usually the DBD plasma consists of many tiny microdischarges (or filaments) of nanosecond or microsecond duration. The homogeneity of the DBD is very desirable for industrial applications especially for surface treatment processes.

Atmospheric plasma source has been developed in a wide range of frequencies from DC to microwave, RF or in a short pulse (Moisan, 1992; Park, 2001; Simor, 2002; Moon, 
2002; Guo, 2003; Moon and Choe, 2004). The characteristics of the discharges are controlled by the operating parameters voltage, frequency, gap width, nature of materials of reactor and nature and operating conditions like gas flow rate, temperature and moisture. In the present study, the discharge was produced by applying $10-30 \mathrm{kHz}, 0$ $-30 \mathrm{kV}$ AC source. The details of the electrical system used in our experiment are also reported earlier (Shrestha, 2007).

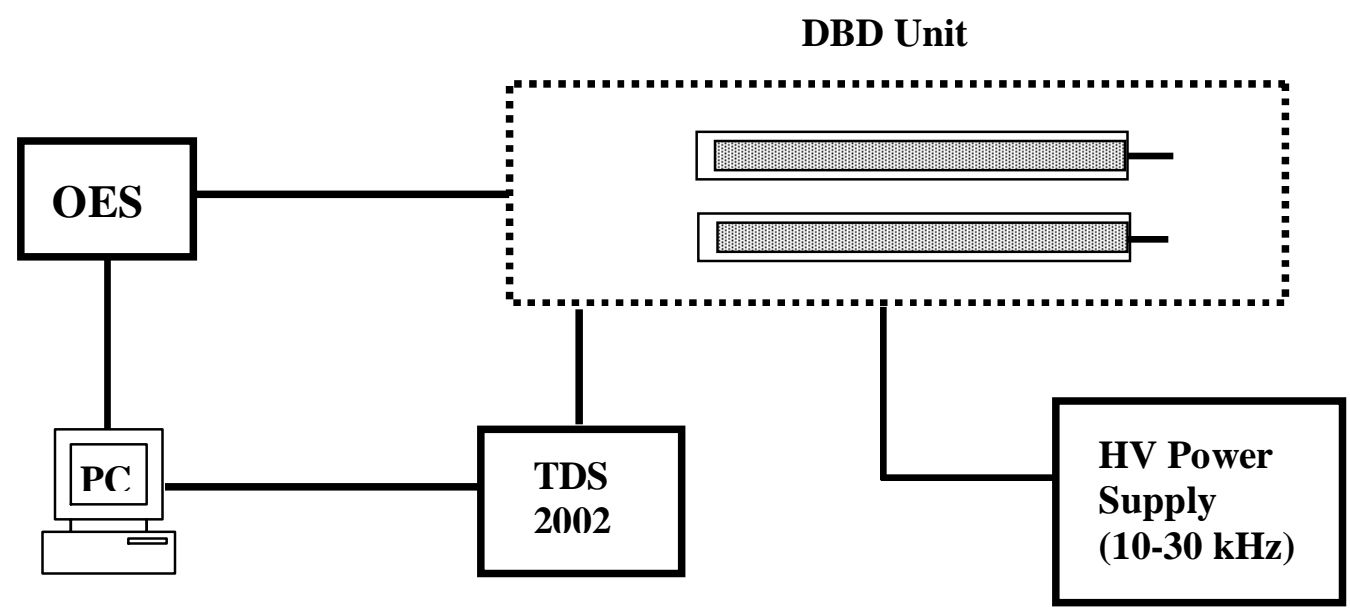

Fig. 1. Schematic diagram of the experimental set-up. OES: Optical Emission Spectrometer, TDS 2002: High Frequency Digital Oscilloscope.

\section{EXPERIMENTAL PROCEDURE}

Fig. 1 shows the schematic diagram of the experimental set-up used in our study. A high voltage power supply of frequency $10-30 \mathrm{kHz}$ was used to generate the discharge in the air gap between two cylindrical electrodes covered by dielectric medium. The power supply was fabricated indigenously at the department of electrical and electronics engineering, Kathmandu University. The electrodes are made of brass and the dielectric material is glass of thickness $2 \mathrm{~mm}$. The current and voltage of the discharge were measured by high frequency digital oscilloscope (Tektronix TDS 2002). For optical characterization, the most commonly used method is optical emission spectroscopy (OES). For OES measurement, the light emitted by the discharge is detected by optical emission spectrometer via an optical fiber. The OES is connected to a personal computer where the corresponding spectra are recorded. The applied voltage, discharge current and spectrum are simultaneously measured and analyzed.

\section{RESULTS AND DISCUSSION}

\section{Electrical Characterization}

Figure 2 shows the voltage and current waveforms of the discharge when the peak voltage was $9.15 \mathrm{kV}$ and peak current $0.28 \mathrm{~mA}$. The DBD is characterized by a number of short life-time micro-discharges created over the surface of the dielectric material. The microdischarges are generated when the applied voltage exceeds the breakdown voltage of the gas. These micro-discharges extinguish when the charge build-up on the dielectric 
reduces the local electric field. Numerous spiky current pulses of micro-discharges are superimposed on the positive and negative half-periods of current waveforms. Power consumed in the discharge corresponds to the product of current and voltage. In the present condition of the discharge the calculated power was found to be equal to $2.56 \mathrm{~W}$. It is important to note that only the spiky parts of current waveforms are used for the formation of reactive species such as $\mathrm{O}, \mathrm{OH}$ and $\mathrm{O}_{3}$. The generation of $\mathrm{OH}$ free radicals in the discharge was indirectly observed by the increased hydrophilicity of a polymer sample treated in the discharge whereas the generation of $\mathrm{O}_{3}$ was detected through the typical ozone odor. Our future work in DBD characterization will be extended to monitoring ozone concentration by chemiluminescene analyzer and a portable flue gas analyzer.

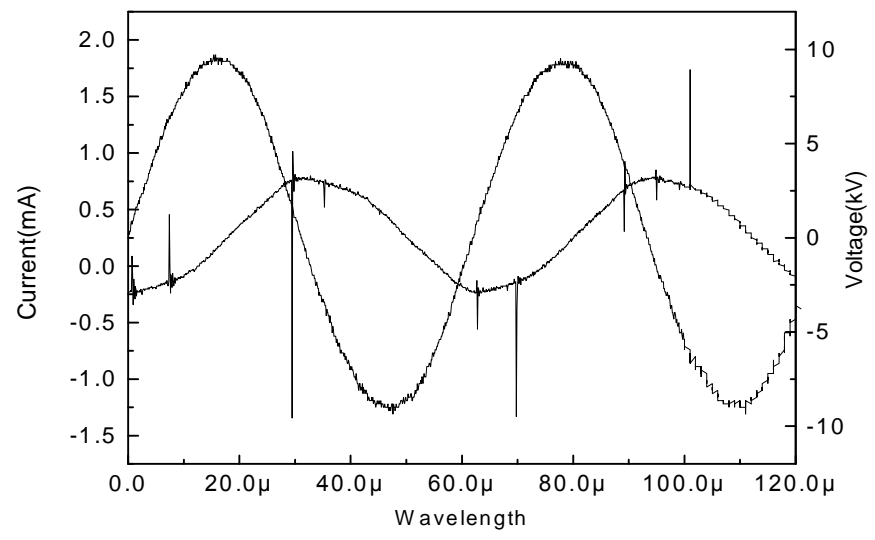

Figure 2: Current and voltage waveforms of a DBD in air with interelectrode gap of $2 \mathrm{~mm}$.

\section{Optical Characterization}

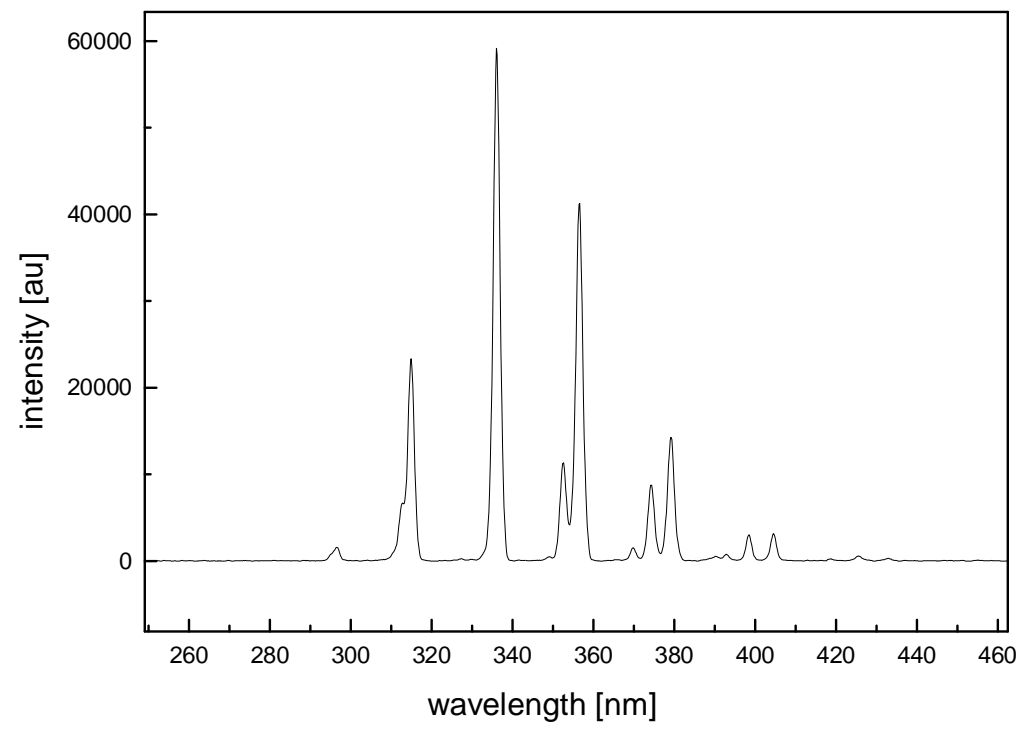

Figure 3 OES of DBD between $250 \mathrm{~nm}$ and $450 \mathrm{~nm}$. 
Figure 3 shows the OES from the discharge between $250 \mathrm{~nm}$ and $450 \mathrm{~nm}$ with $2 \mathrm{~mm}$ electrode gap. Four suitable lines (two for NI and NII) are chosen and electron temperature is estimated using the line intensity ratio method. For the measurement of electron temperature, the following equation is used.

$$
\frac{R_{1}}{R_{2}}=\frac{I_{1} / I_{2}}{I_{3} / I_{4}}=\left(\frac{A_{p q}}{A_{x y}}\right)\left(\frac{g_{p}}{g_{x}}\right)\left(\frac{\lambda_{x y}}{\lambda_{p q}}\right)\left(\frac{A_{u v}}{A_{r s}}\right)\left(\frac{g_{u}}{g_{r}}\right)\left(\frac{\lambda_{r s}}{\lambda_{u v}}\right) \exp \left[-\frac{E_{p}-E_{x}-E_{r}+E_{u}}{k T_{e}}\right]
$$

where $R$ is the ratio of intensity of two lines, $I$ is the intensity of the spectral line, $A_{i j}$ is the transition probability of transition $\mathrm{i} \rightarrow \mathrm{j}, \mathrm{g}_{\mathrm{i}}$ is the statistical weight of the upper level, $\lambda$ is the wavelength of line radiation, $\mathrm{E}_{\mathrm{i}}$ is the energy of the upper level, $\mathrm{k}$ is Boltzmann constant and $T_{e}$ is electron temperature. The value of $\lambda$ and $I$ are obtained from the observation, and the values of $\mathrm{A}_{\mathrm{ij}}$, $\mathrm{g}_{\mathrm{i}}$, and $\mathrm{E}_{\mathrm{i}}$ are obtained from NIST atomic Spectra Database. Considering two NI lines with wavelengths $381.02 \mathrm{~nm}$ and $426.9 \mathrm{~nm}$ and two NII lines with wavelengths $392.12 \mathrm{~nm}$ and $409.6 \mathrm{~nm}$ we obtain,

$$
\begin{aligned}
& \mathrm{A}_{\mathrm{pq}}=\mathrm{A}_{\mathrm{NI}}(381.02 \mathrm{~nm})=8.95 \times 10^{5} \mathrm{~s}^{-1}, \mathrm{gp}=4, \mathrm{E}_{\mathrm{p}}=13.92 \mathrm{eV} \\
& \mathrm{A}_{\mathrm{rs}}=\mathrm{A}_{\mathrm{NI}}(426.98 \mathrm{~nm})=2.26 \times 10^{6} \mathrm{~s}^{-1}, \mathrm{gr}=4, \mathrm{E}_{\mathrm{r}}=14.92 \mathrm{eV} \\
& \mathrm{A}_{\mathrm{xy}}=\mathrm{A}_{\mathrm{NII}}(392.12 \mathrm{~nm})=7.99 \times 10^{6} \mathrm{~s}^{-1}, \mathrm{gx}=5, \mathrm{E}_{\mathrm{x}}=28.34 \mathrm{eV} \\
& \mathrm{A}_{\mathrm{uv}}=\mathrm{A}_{\mathrm{NII}}(409.6 \mathrm{~nm})=8.05 \times 10^{4} \mathrm{~s}^{-1}, \mathrm{gp}=4, \mathrm{E}_{\mathrm{p}}=15.03 \mathrm{eV}
\end{aligned}
$$

Using the above data we obtain, $\frac{R_{1}}{R_{2}}=8.95 \times 10^{-5} \exp \left[\frac{14.31}{k T e}\right]$

Figure 4. shows the plot between $R_{1} / R_{2}$ and Te with different values of Te. This graph is used to determine the electron temperature using the value of $R_{1} / R_{2}$ obtained from the observation. From the observation, $\mathrm{R}_{1} / \mathrm{R}_{2}=\frac{I_{1} / I_{2}}{I_{3} / I_{4}}=10.8$ which corresponds to electron temperature of $1.9 \mathrm{eV}$. From the observed values of $\mathrm{R}_{1} / \mathrm{R}_{2}$ it can be concluded that the electron temperature lies between $1 \mathrm{eV}$ and $2 \mathrm{eV}$.

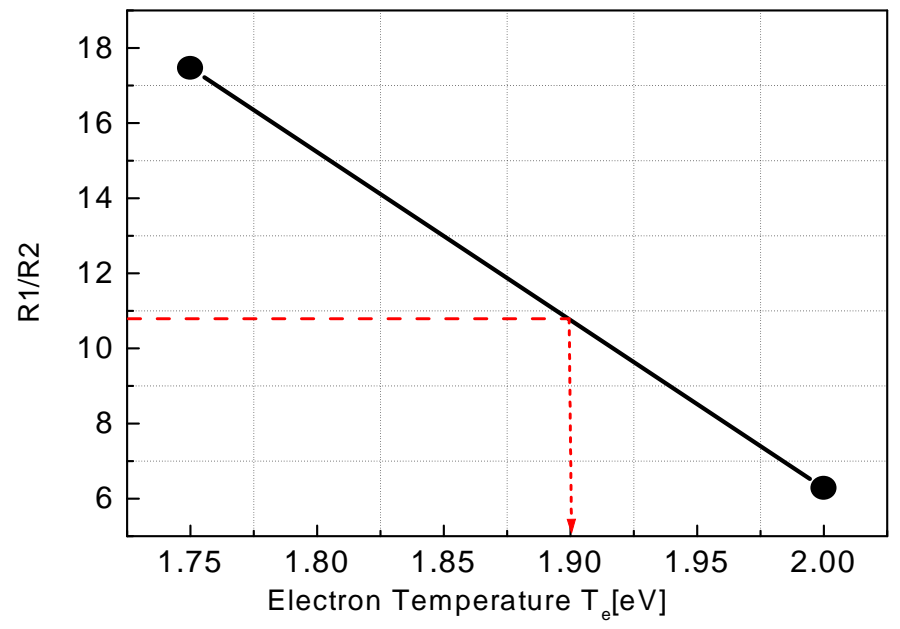

Figure 4 . The plot between $R_{1} / R_{2}$ and Te with different values of Te. 
Figure 5. shows the photograph of the glow like discharge produced between the electrodes when the applied voltage was $6.69 \mathrm{kV}$ at a frequency of $19.19 \mathrm{KHz}$. The interelectrode gap was $2 \mathrm{~mm}$ and the discharge current $0.36 \mathrm{~mA}$. With the increase in frequency of the applied voltage to about $20 \mathrm{kHz}$ the discharge appears to be similar to atmospheric pressure glow discharge (APGD). At lower frequency the discharge consists of several inhomogeneous filaments.

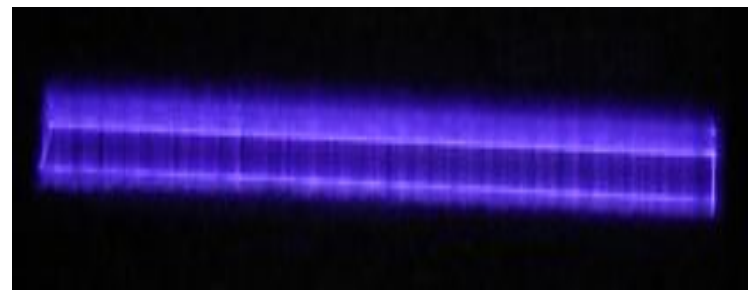

Figure 5: Photograph of the discharge. The Discharge conditions were: Frequency $=$ $19.19 \mathrm{kHz}$, Voltage $\mathrm{V}_{\mathrm{rms}}: 6.69 \mathrm{kV}, \mathrm{I}_{\mathrm{rms}}=0.36$ $\mathrm{mA}$. Electrode spacing $\mathrm{d}=2 \mathrm{~mm}$

Cylindrical Electrode

\section{CONCLUSIONS}

Atmospheric pressure plasma which uses a dielectric barrier discharge has been developed indigenously in our laboratory. The general characteristics such as current in the discharge, discharge power and the optical emission spectra in our study has been found to be similar with APGD. The electron temperature of about $1.9 \mathrm{eV}$ was determined. The discharge has been successfully applied for the hydrophilization of low density polyethylene. Investigation on water treatment by DBD is also in progress.

\section{ACKNOWLEDGEMENT}

The authors would like to thank Prof. C.S Wong, Department of Physics, University of Malaya, Kuala Lumpur, Malaysia. We are also thankful to Dr. Peter Freere for his help in developing the power supply. This research was supported by the International Foundation for Science (IFS) Stockholm, Sweden, and the Organization for the Prohibition of Chemical Weapons, The Hague, The Netherlands, through a grant to Dr. D.P. Subedi.

\section{REFERENCES}

1. M. J Shenton and G.C. Steven 2001. J. Appl. Phys 34 2761-8,

2. Z Y Fang Qiu and Y Luo 2003. J. Phys. D: Appl.

3. U.Kogelschatz, B.Eliasson, and W.Egli, in Proc. Ispc 14, Prague, 1999, p.3

4. J. Tepper, M.Lindmayer and B.Juttner, in XIII int. conf., Scotland 03-08 September 2000. 
5. Fridman A, chirokov A and Gustol A 2005. Non-thermal atmospheric pressure discharges J. Phys. D: Appl. Phys.38 R1-24

6. Hammer T 1999 Application of plasma technology in environmental techniques Contrib. Plasma Phys.39 441-62

7. McAdams R 2001. Prospects for non thermal atmospheric plasmas for pollution abatement J. Phys. D: Appl.Phys. 34 2810-21

8. Bogaerts A,Neyts E, Gijbels and Van Der Mullen J 2002. Gas discharge plasmas and their applications Spectrochim, Acta B 57 609-58

9. Borcia G, Chiper A and Rusu I, 2006 Plasma Sources Sci. Technol 15: 849-857

10. S. Y. Moon, W. Choe, B.K. Kang, 2004. Applied physics lett. 84, Number 2

11. M.Moisan,J.Hubert, J.Margpt, G.Sauve, and Z. Zakrzewki, 1992. Microwave Discharge: Fundamental and Application, edited by C.M. Ferreira and M.Moisan (Plenum, New York), Chep. 1

12. J.Park, I.Henins, H.W.Hermann, and G.S. Selwyn, 2001. J.Appl. Phys 89:15

13. M.Simor, J. Rahel', P. Vojtek, M. Cernak, and A. Brablec, 2002. Apply.Phts.Lett. 81: 216.

14. S.Y.Moon,W.Choe, H.S.Uhm, Y.S. Hwong, and J. J. Choi, 2002. Phys. Plasma 9: 4045

15. Y.B. Guo and F.C. N. Hong, 2003. Appl, Physs. Lett. 82,337.

16. G. Shrestha, P. Freere, S. M. Basnet, W.T. Jewel, D. P. Subedi, 2007. Development of a Cold Plasma Generator for Atmospheric Pressure Dielectric Barrier Discharge, IEEE, Region 5 Technical Conference, pp. 432-435. 